\title{
Estudo das alterações oxidativas, da capacidade antioxidante total e do óxido nítrico, em ratos submetidos à isquemia e reperfusão de membros posteriores ${ }^{1}$
}

\author{
Oxidatives alterations, total antioxidant status and nitric oxide study in rats submitted \\ to ischemia and reperfusion of hind limbs.
}

\author{
Acacio Francisco Neto ${ }^{2}$, José Carlos Costa Baptista Silva ${ }^{3}$, Djalma José Fagundes ${ }^{4}$, Sandro Percário ${ }^{5}$, Neil Ferreira \\ $\mathrm{Novo}^{6}$, Yara Juliano ${ }^{7}$, Antonio Augusto Moreira Neto $^{8}$. \\ 1. Tese de Doutorado apresentada à UNIFESP-EPM. \\ 2. Mestre em Técnica Operatória e Cirurgia Experimental pela UNIFESP-EPM. \\ 3. Prof. Associado Livre Docente do Depto de Cirurgia da UNIFESP-EPM. \\ 4. Coordenador do Programa de Pós-Graduação em Tec. Op. e Cir. Experimental da UNIFESP-EPM \\ 5. Prof. Dr. da Disciplina de Bioquímica da Universidade de Sorocaba UNISO. \\ 6. Prof. Adjunto da Disciplina de Bioestatística do Depto de Med. Preventiva da UNIFESP-EPM \\ 7. Profa. Adjunta da Disciplina de Bioestatística do Depto de Med. Preventiva da UNIFESP-EPM \\ 8. Médico, Cirurgião Vascular da Santa Casa de Mogi das Cruzes.
}

\section{RESUMO}

Objetivo: Verificar o efeito do tempo de isquemia sobre as alterações oxidativas, a capacidade antioxidante total e o óxido nítrico, no músculo, no rim e no plasma de ratos submetidos à isquemia e reperfusão de membros posteriores. Métodos: 40 ratos machos foram distribuídos aleatóriamente em quatro grupos experimentais com 10 animais cada. Laparotomia, isolamento da aorta abdominal infra e justa renal. Grupos 1 e 3 (simulados) passagem do fio monofilamentar de polipropileno 7-0 ao redor da aorta sem liga-la e espera de 1 hora para o grupo 1 e de 6 horas para o grupo 3. Retirada do fio, espera de 15 minutos, eutanásia e colheita do material. Grupos 2 e 4 (experimentos), ligadura da aorta abdominal com o mesmo fio e isquemia de 1 hora no grupo 2 e de 6 horas no grupo 4. Retirada do fio e reperfusão por 15 minutos. Eutanásia e colheita de sangue por escoamento, músculo da pata posterior esquerda e rim esquerdo. Os parâmetros verificados foram: malondialdeído, capacidade antioxidante total e óxido nítrico. Resultados: Utilizou-se o teste “t”de Student e o teste de MANN-WHITNEY como testes não paramétricos e fixou-se em 0,05 ou 5\% o nível de rejeição. Houve alterações estatísticamente significantes do malondialdeído no rim. A capacidade antioxidante total apresentou alterações significantes no rim, no músculo e no plasma enquanto que, o óxido nítrico, alterou apenas no plasma. Conclusão: A variação do tempo de isquemia provocou alterações significantes do malondialdeído, da capacidade antioxidante total e do óxido nítrico. Descritores: Isquemia. Reperfusão. Radicais livres. Estresse Oxidativo. Ratos

\begin{abstract}
Purpose: To verify the effect of the ischemia time on the oxidative alterations, total antioxidant status and the nitric oxide, in the muscle, kidney and plasma, in rats submitted to ischemia and reperfusion of hind limbs. Methods: Forty male rats were randomized in four groups with ten animals each. Laparotomy, abdominal aorta infra e juxta renal isolation. Groups 1 and 3 (sham), passage of the polipropilen 7.0 monofilamentary thread aorta around without bending it and waiting time of 1 hour to group 1 and 6 hours to group 3. Withdrawal of the thread, waiting time of 15 minutes, euthanasia and material collection. Groups 2 and 4 (experiments), ligation of abdominal aorta with the same thread and ischemia of 1 hour in the group 2 and 6 hours to the group 4. Withdrawal of the thread and reperfusion for 15 minutes. Euthanasia and blood collection by flowing; withdrawal of the left hind limb muscle and of the left kidney. The parameters evaluated were: malondialdehyde, total antioxidant status and the nitric oxide. Results: The "T"Student test and the MANN-WHITNEY test have been used as nonparametrics tests and the rejection level have been fixed in 0,05 or $5 \%$. There were significative alterations of the malondialdehyde in the kidney. The total antioxidant status has been shoun significative alterations in the kidney, muscle and plasma. Although the nitric oxide has been altered in the plasma only. Conclusion: The ischemia time changing has provoked significative alterations of malondialdehyde, total antioxidant status and nitric oxide.
\end{abstract}

Key words: Ischemia. Reperfusion. Free radicals. Oxidative stress. Rats. 


\section{Introdução}

A isquemia em membros inferiores provoca sinais e sintomas decorrentes da insuficiência arterial, nos tecidos de um determinado segmento do corpo humano, com risco de perda de partes ou de todo o membro se o tratamento não for eficiente ${ }^{1}$. As principais conseqüências da isquemia ocorrem em território arteríolo-capilar e, em persistindo a isquemia, surgem as primeiras áreas de necrose capilar e tecidual ${ }^{2}$. A tolerância dos tecidos a isquemia é variável e multifatorial dependendo do tempo de isquemia, das necessidades metabólicas dos tecido, do aporte da circulação colateral e de fatores humorais. Sendo assim, não se pode determinar com precisão para cada tipo de tecido, um período de “isquemia segura” aquém do qual a sua vitalidade não ficaria comprometida irreversívelmente ${ }^{3}$. Com a persistência da isquemia surgem áreas de necrose e, em determinado momento, existirá áreas de tecido normal entremeadas com áreas de tecido funcionalmente alterados, mas viáveis, juntamente com áreas de tecido necrosado. Quando a circulação é restaurada e inicia-se o processo de reperfusão, tecidos viáveis se recuperam e voltam a sua função e os tecidos necrosados sofrem processos de reabsorção, organização e fibrose. Ocorrerá, então, conseqüências bioquímicas, hemodinâmicas e anátomopatológicas em extensão variável. O aparecimento de metabólitos celulares na corrente circulatória leva a alterações imediatas da função renal entre outras modificações. Isso sempre vai ocorrer quando grandes áreas musculares são afetadas e a isquemia for prolongada ${ }^{2}$. Por ser um evento clínico freqüente a isquemia se apresenta ao cirurgião vascular com uma forte indicação para ato cirúrgico restaurador.Se, por um lado, essa restauração do fluxo sangüíneo é, em geral, necessária para se recuperar a função celular normal, por outro lado, a re-introdução do sangue oxigenado nos tecidos isquêmicos pode desencadear lesões teciduais ainda mais intensas do que as provocadas pela isquemia "per se”. Esse agravamento das lesões teciduais foi chamado de "paradoxo do oxigênio"4. McCord propôs que o mecanismo responsável por esse agravamento seria a geração de radicais livres de oxigênio conseqënte a reintrodução de oxigênio molecular ${ }^{5}$. Sabe-se que radicais livres são gerados na isquemia e reperfusão causando complicações ${ }^{6}$. Radicais livres são moléculas instáveis ou fragmentos de moléculas sem um par de elétrons em suas órbitas exteriores. Incluem-se o radical superóxido, o peróxido de hidrogênio e o radical hidroxila7. Os radicais hidroxila atuando sobre os lipídios, carboidratos, proteínas e ácidos nucleicos, em um fenômeno chamado "estresse oxidativo”, levam a modificações da função e da estrutura celular podendo levar a célula a morte ${ }^{8}$. O estresse oxidativo, que corresponde a produção de radicais livres sobrepujando a defesa antioxidante, provoca uma rápida degeneração da função da célula endotelial ${ }^{8,9}$. O endotélio deve ser encarado não como uma barreira passiva entre o fluxo sangüíneo e o organismo e, sim, como um sistema orgânico cuja função é crítica na manutenção da anticoagulação sangüínea in vivo, na manutenção do tono vascular e na regulação da perfusão. Para essa manutenção substâncias vasoativas derivam do endotélio. São elas: prostaciclina, fator relaxante derivado do endotélio sendo verificado tratar-se do óxido nítrico, fator hiperpolarizante e fatores contráteis ${ }^{10}$. O óxido nítrico que mantém um estado de vasodilatação persistente pode, com o aparecimento dos radicais livres, tornar-se um potente oxidante ao combinar-se com o radical hidroxila ${ }^{11}$. As pesquisas básicas mostraram, claramente, os mecanismos fisiopatológicos do envolvimento de radicais livres na genese das lesões teciduais, na síndrome de isquemia e reperfusão ${ }^{3}$. Várias alternativas terapêuticas potenciais surgiram desses conhecimentos direcionadas, fundamentalmente, no bloqueio direto dos radicais livres, na inativação de enzimas ou metais, na interrupção das reações em cadeia de lipoperoxidação e, no bloqueio da chegada e da atividade dos neutrófilos ${ }^{3,12}$. Fundamentalmente, essas alternativas utilizaram vasodilatadores e anticoagulantes ${ }^{13,14}$. No entanto, a aplicação clínica desses conhecimentos básicos não proporcionaram efeitos benéficos evidentes. Em função disso, alguns autores chegam a contestar a importância da reperfusão considerando que, talvez, a isquemia fosse por si só a causa da maior parte das alterações na isquemia e reperfusão ${ }^{3}$. A utilização de uma substância protetora na fase isquêmica, em trabalho experimental, antes da reperfusão em cérebro de coelhos mostrou bons resultados reforçando a importância do tempo de isquemia ${ }^{15}$. A possibilidade de alterações oxidativas ocorrerem já de forma acentuada no período isquêmico e, não apenas quando da re-introdução do oxigênio, estimulou esta pesquisa onde, variando-se o tempo de isquemia, procurou-se a resposta do organismo em relação ao malondialdeído, a capacidade antioxidante total e o óxido nítrico.

\section{Métodos}

Foram utilizados 40 ratos machos adultos da linhagem EPMI-WISTAR, com idade média de 105 dias e peso corpóreo médio de 300 gramas, provenientes do Biotério Central da UNIFESP-EPM e mantidos sob condições controladas. Todos os animais foram manipulados de acordo com “OS Princípios Éticos da Experimentação Animal da União Internacional Protetora dos Animais"e da Lei 6638 de maio de 1979 e aprovação do Comitê de Ética da UNIFESPEPM sob o número 0663/03. Este trabalho não tem conflito de interesses (ANVISA e CFM). Os animais foram distribuídos aleatoriamente em quatro grupos com 10 animais em cada grupo. Grupos Sham I e Sham II foram os grupos simulados e grupos Isquemia I e Isquemia II foram os grupos experimentos. Todos os animais foram préviamente anestesiados com hidrato de cloral a $50 \%$ na dose de $0,4 \mathrm{~m} ; \mathrm{Kg}^{-1}$ por via peritoneal. Submetidos a epilação abdominal foram colocados em decúbito dorsal sobre a mesa operatória com as patas atadas a mesa com fitas elásticas. Anti-sepsia com álcool iodado a 3\% e laparotomia mediana de aproximadamente $4 \mathrm{~cm}$. Afastamento das alças intestinais para a direita, dissecção cuidadosa da aorta abdominal e visibilização da veia renal esquerda. Nos grupos simulados I e II passagem de fio monofilamentar de polipropileno 7-0 ao redor da aorta justa e infra veia renal E sem liga-la. Permanência do fio por 1 hora no grupo simulado I e por 6 horas no grupo simulado II. Re-operação para retirada do fio e observação por 15 minutos. Nos grupos Isquemia I e II passagem do fio monofilamentar e ligadura da aorta 
abdominal justa e infra veia renal esquerda permanecendo essa ligadura por 1 hora no grupo isquemia I e por 6 horas no grupo isquemia II. A eficácia da ligadura foi comprovada pelo aparecimento de palidez e ou cianose, esfriamento dos membros posteriores e ausência de visibilização das pulsações sob visão de microscopia óptica. Re-operação para retirada do fio e reperfusão por 15 minutos. Uma vez terminado o tempo experimental os animais foram submetidos a eutanásia através da guilhotina, com coleta do sangue por escoamento, retirada do bloco muscular da pata traseira esquerda e retirada do rim esquerdo. O sangue coletado foi colocado em tubo de ensaio contendo heparina sódica e o grupo muscular e o rim lavados em solução salina picotados e homogeinizados com solução tampão salina fosfato e centrifugados. Uma vez preparado o material procedeu-se a avaliação: da capacidade antioxidante total (TAS) através do Kit Total Antioxidant Status (Randox Laboratories); do Malondialdeído (MDA) segundo método proposto por Khon \& Liversedge modificado por Percário ${ }^{8}$ e do óxido nítrico (NO) através do Kit Nitrate/Nitrite Colorimetric Assay Kit (Cayman Chemical).

\section{Resultados}

Para análise dos resultados utilizou-se testes paramétricos e não paramétricos levando-se em conta as variáveis estudadas, Foram aplicados os testes " $t$ "de Student ${ }^{16}$ e o teste de Mann-Whitney ${ }^{17}$ fixando-se em 0,05 ou 5\% o nível para a rejeição da hipótese de nulidade. A dosagem do MDA no músculo esquelético, apesar de não apresentar significância estatística, mostrou-se mais elevado no grupo experimento do que no grupo simulado. A TAS dosada no músculo mostrou diferença estatísticamente significante quando comparados os grupos isquemia 1 hora e isquemia 6 horas.(gráfico 1) O NO, no músculo, variou quando comparados os grupos isquemia entre sí mas sem significância estatística.

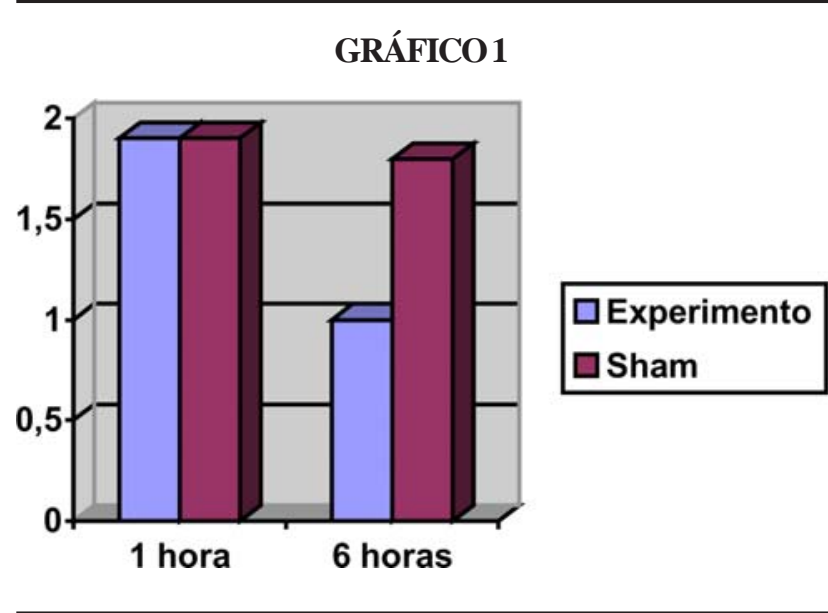

As dosagens do MDA no rim foi estatísticamente significante quando comparados os grupos isquemia 1 hora e seu respectivo simulado. Houve também diferença quando comparados os grupos isquemia entre sí mas, sem significância estatística.(gráfico 2) A TAS mostrou diferença estatísticamente significante quando comparados os grupos isquemia entre sí.(gráfico 3) O NO também mostrou

\section{GRÁFICO 2}

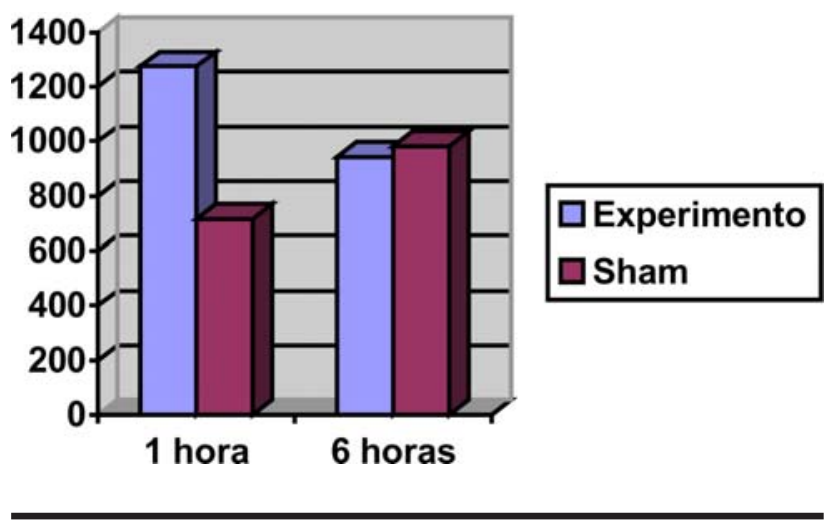

GRÁFICO3

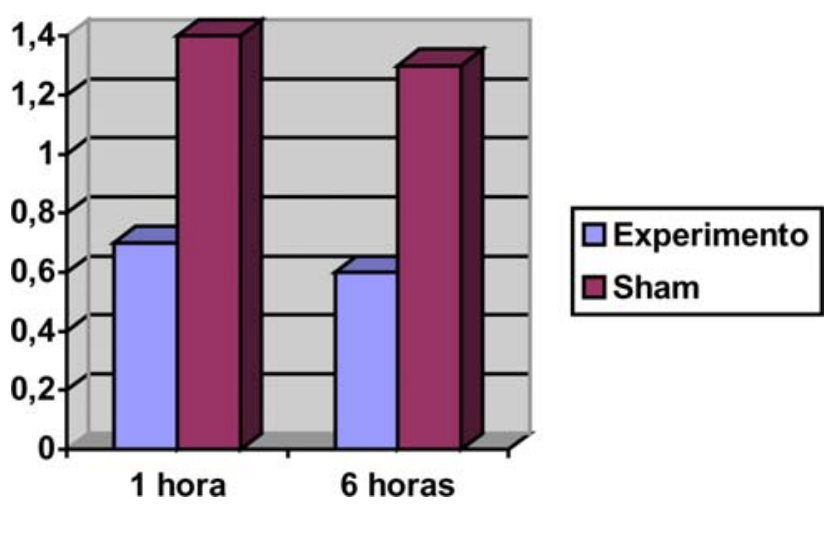

diferença entre os grupos isquemia, porém, sem significância estatística. As dosagens realizadas no plasma mostraram variação do MDA no grupo isquemia 1 hora comparado com o seu simulado sem significância estatística; a TAS variou estatísticamente significante entre os grupos isquemia 1 hora e 6 horas(gráfico 4). O NO mostrou uma queda quando comparados os grupos isquemia mas, sem significância estatística.(gráfico 5)

\section{GRÁFICO 4}

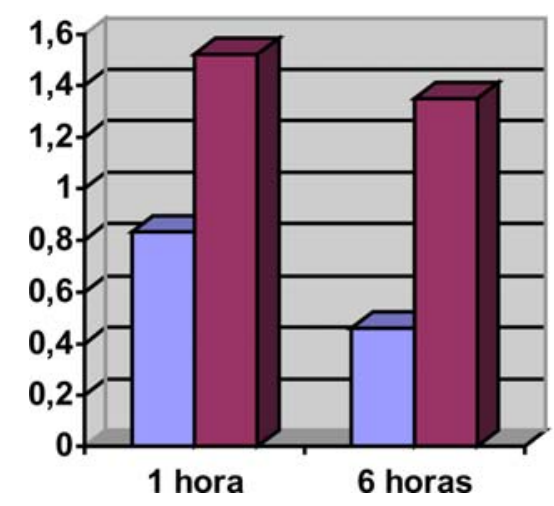

Experimento

$\square$ Sham 


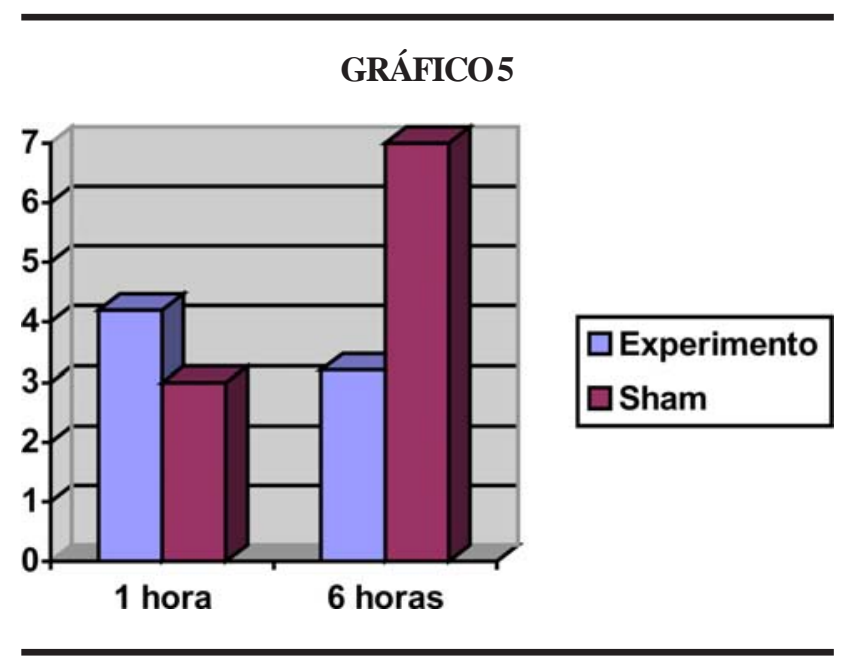

Discussão

Isquemia, por definição, é ausência de fluxo sangüíneo e conseqüente redução ou ausência da oferta de oxigênio e substratos ao tecido e excesso de metabólitos ${ }^{1}$. No ser humano, a isquemia aguda pode levar, se não restabelecido fluxo sangüíneo, desde pequenas necroses até a amputação dos membros ${ }^{3}$. No entanto, o restabelecimento do fluxo arterial após isquemia aguda resulta, geralmente, na recuperação morfológica-funcional mas, em alguns casos, aparece uma síndrome pós-revascularização complexa levando, ás vezes, a perda de membros ou da vida. ${ }^{2,22,23}$. Dois fatores tem importância na síndrome isquemia e reperfusão: a)lesão celular direta pela produção de radicais livres e peroxidação lipídica; lesão celular indireta pela incapacidade de restaurar a perfusão microvascular, formação de trombos, lesão endotelial e empilhamento leucocitário ${ }^{23}$. Fisiológicamente o organismo pode se defender da agressão mediada pelos radicais livres utilizando as reservas antioxidantes celulares. Estas reservas são constituídas por tres sistemas de defesa antioxidante: enzimático, moléculas pequenas e o sistema de quelação de metais. Muitas pesquisas e revisões foram realizadas mostrando diferentes respostas ao estresse oxidativo envolvendo o MDA, a TAS e o NO. Estas pesquisas apresentavam diferentes metodologias, outros órgãos ou tecidos estudados ${ }^{1,7,9,11,14,15,20,21,24,26,29-30}$. Trabalhos experimentais utilizaram o músculo esquelético de intestino de rato para o estudo de sua resistência à isquemia total e posterior reperfusão. Concluiu ser o mesmo resistente porque havia um aumento do íon magnésio intramitocondrial protegendo-o. Essa avaliação foi feita dosando-se, no intestino, o MDA, a TAS e o $\mathrm{NO}^{20,27}$. A dosagem do MDA, para caracterizar dano tecidual, foi utilizada em diferentes experimentos utilizando ora o músculo cardíaco de ratos ora o cérebro de coelhos impossibilitando uma cotização dos resultados com o trabalho realizado ${ }^{6,13,25,30}$. Neste experimento, onde variouse o tempo de isquemia (1 hora e 6 horas), o resultado das dosagens do MDA no músculo esquelético, apesar de não apresentar significância estatística, mostrou-se mais elevado no grupo experimento do que no grupo simulado. Apesar da impossibilidade de comparação com os trabalhos citados anteriormente o MDA dosado nesta pesquisa mostrou que a resistência do músculo esquelético à isquemia é relativa e parece depender do tempo de isquemia. Um aumento maior do MDA parece não ter acontecido pela resposta global do organismo mobilizando sua defesas antioxidantes. A TAS tem a finalidade de mostrar a resposta do organismo ao agente agressor estudado, ou seja, aos radicais livres. Sabese que esta capacidade tem um limite ${ }^{3,11}$. Quando a produção de radicais livres sobrepuja a capacidade de defesa antioxidante, inicia-se o fenômeno do ëstresse oxidativo"resultando em distúrbio morfológico-funcional da célula lesada ${ }^{8}$. Trabalhos pesquisados estudaram a capacidade antioxidante total em tecidos diferentes dos estudados nesta pesquisa inclusive com metodologia diferente o que dificultou a comparação dos resultados ${ }^{8,20,21}$. Sabendo-se a função da TAS observou-se, no músculo esquelético, variando o tempo de isquemia, uma queda acentuada da mesma após 6 horas o que sugeriu a queda da capacidade de defesa do organismo com o aumento do tempo de isquemia. O NO foi o mais estudado nos trabalhos pesquisados provavelmente por mostrar a resposta endotelial ${ }^{3,8-10,13,24-26,28-30}$. No entanto, nenhum dos trabalhos citados procurou variar o tempo de isquemia e observar o que aconteceria com o óxido nítrico. Apenas um experimento, realizado com seres humanos, mostrou que, quando o músculo esquelético foi submetido a hipóxia, havia uma diminuição do óxido nítrico. No entanto, depois de uma isquemia prolongada (1 hora), ocorreu um aumento evidente do óxido nítrico, resultado observado no músculo esquelético após biópsias. Quando restaurada a circulação o nível de NO foi progressivamente normalizando ${ }^{25,30}$. Nesta pesquisa houve um aumento do NO no grupo isquemia 1 hora e uma diminuição no grupo isquemia 6 horas. Como o óxido nítrico é um vasodilatador produzido pelo endotélio era de se esperar que com aumento do tempo de isquemia houvesse um aumento na produção do NO na tentativa de restabelecer a oferta de oxigênio ao tecido isquêmico. Isso pode significar ou cessação do estímulo para produzir óxido nítrico ou que o estresse oxidativo tenha causado lesão endotelial com conseqüente diminuição da capacidade de produção do NO. Os dados obtidos poderiam sugerir a importância do tempo de isquemia em relação a resposta endotelial para produzir o NO. Já em 1941 chamava-se a atenção para a síndrome metabólica complexa que a isquemia e reperfusão de membros inferiores desencadeava principalmente com alterações sofridas pelos rins ${ }^{30}$. Posteriormente, essas alterações foram denominadas de síndrome mionefropática ${ }^{2,3,12,22,23}$. Devido a isso o rim é utilizado como órgão a ser estudado na síndrome de isquemia e reperfusão de membros inferiores. O MDA dosado no rim neste experimento mostrou-se alterado em todas as comparações mas os resultados em nada diferiram dos obtidos na literatura ${ }^{12,23}$. A TAS mostrou uma queda acentuada, estatísticamente significante, quando comparados os grupos isquemia entre sí. Isto reforça a hipótese do consumo da defesa antioxidante. O mesmo ocorreu com o NO se comparados os grupos isquemia mas, sem resultados estatísticamente significantes. O terceiro tecido escolhido para a realização das dosagens foi o plasma para podermos observar a resposta do organismo como um todo. O MDA elevou-se apenas no grupo isquemia 1 hora e depois manteve-se inalterado no grupo isquemia 6 horas. 
Isso pode significar que o estresse oxidativo não tenha sido importante no plasma. Já a TAS mostrou alterações siginificantes quando comparados os grupos isquemia entre sí. Isso vem mostrar a resposta do organismo na defesa antioxidante e, por sua diminuição progressiva entre os grupos, sugere o comprometimento das reservas mobilizáveis do organismo. O NO dosado no plasma mostrou um aumento no grupo isquemia 1 hora e uma queda no grupo 6 horas. Esse fato pode sugerir um aumento de oferta pelo organismo e posterior impossibilidade de manter essa oferta seja por lesão endotelial, seja pela impossibilidade do próprio organismo aumentar sua produção. Esta possibilidade parece ser reforçada quando se comparou o grupo isquemia 6 horas com seu respectivo simulado.

\section{Conclusões}

A variação do tempo de isquemia provocou:

a) alterações do malondialdeído(MDA) no rim;

b) alterações da capacidade antioxidante total(TAS) no rim, músculo e plasma;

c) alteração do óxido nítrico(NO) no plasma.

\section{Referências}

1. Silva JCCB, Burihan E. Diagnóstico clínico da isquemia crítica dos membros. Rev Bras Clin Ter. 1999;25:71-9.

2. Ramaciotti O. Síndrome isquêmica aguda. Manual de Angiologia para o Clínico. 1974;89-100.

3. Yoshida WB. Radicais livres na síndrome da isquemia e reperfusão. Cir Vasc Angiol. 1996;12:82-95.

4. Hearse DJ, Humprey WG, Bullock GR. The oxygen paradox and the calcium paradox: Two facets of the same problem? J Moll Cell Cardiol. 1978;10:641-68.

5. McCord JM. Oxygen-derived free radicals in postischemia tissue injury. N Engl J Med. 1985;159-63.

6. Freisleben HJ. Lipoate ameliorates ischemia-reperfusion in animal models. Clin Hemorheol Microcirc. 2000;23:219-24.

7. Córdova A, Navas JF. Os radicais livres e o dano muscular produzido pelo exercício: papel dos antioxidantes. Rev Bras Med Esporte. 2000;6:204-8.

8. Percário S. Alterações oxidativas e da defesa antioxidante no broncoespasmo agudo induzido em cobaias. [Tese de Doutorado]. São Paulo (SP): UNIFESP-EPM. 2000.

9. Simonini G, Pignone A, Generini S, Falcini F, Cerinic MM, Gabriele S, Alberto P, Sérgio G, Fernanda F, Marco MC. Emerging potentials for antioxidant therapy a new approach to the Treatment of systemic sclerosis. Toxicology. 2000;155:1-15.

10.Evora PRB, Garcia LV, Nobre F, Viaro F. Endotélio e óxido nítrico: do laboratório à prática clínica. Revista de Medicina, Ribeirão Preto. 1999;32:65-81.

11.Boveris A. Biochemistry of free radicals: from electrons to tissues. Medicina. 1998;58:350-6.

12.Souza-Moraes MR, David-Filho R, Baptista-Silva JCC, Ullian M, Franco MF, Gabriel Jr. A, Smith B, Burihan E. Effect of antibodies to intercellular adhesion molecule type 1 on the Protection of distant organs during reperfusion syndrome in rats. Braz J Med Biol Res. 2003;36:605-12.
13. Coe DA, Freischlag JÁ, Johnson D, Mudaliar JH, Kosciesza AS, Traul DK, Chiang PC, Cambria RA, Seabrook GR, Townw JB. Pentoxifylline prevents endothelial damage due to ischemia and reperfusion injury. J Surg Res. 1997;67:21-5.

14.Luther B, Lehmann Ch, Grune T, Meyer R, Schwenke G, Beutel H, Bürger K. Kontrollierte reperfusion iscämischer extremitätenmuskulatur zur vermiderung radikalischer läsionen. Zentralbl Chir. 1999;124:336-43.

15.Pluta RM, Rak R, Wink DA, Woodward JJ, Khaldi A, Oldfield $\mathrm{EH}$, Watson JC. Effects of nitric oxide on reactive oxygen species production and infarction size after brain reperfusion injury. Neurosurgery. 2001;48:884-93.

16.Sokall RR, Rohlf FJ. Biometry. W.H Freeman and Company San Francisco. 1969;776.

17.Siegel S \& Castellan Jr NJ. Nonparametric Statistics. Second Edition. McGraw Hill Int Ed. N. York. 1988;399.

18.Haimovich H. Vascular Surgery. McGraw Hill. 1973.

19.Takito AM. Estudo funcional e histológico renal na síndrome de isquemia e reperfusão em membros posteriores de ratos. [Tese de Mestrado]. São Paulo (SP): UNIFESP-EPM. 1999.

20.Balogh N, Krausz F, Lévai P, Ribiczeync PS, Vajdovich P, Gaál T. Effect of defexoramine and L-arginine treatment on lipid peroxidation in intestinal ischaemia-reperfusion model in rats. Acta Vet Hung. 2002;50:343-56.

21.Cuzzocrea S, Chaterjee PK, Mazzon E, Dugo L, De SarroA, Van de Loo FA, Caputi AP, Thiemerman C. Role of induced nitric oxide in the initation of the inflammatory response After postischemic injury. Shock. 2002;18:169-76.

22.Traber DI. Nitric oxide synthase and tissue injury. Shock. 2000;14:243-4.

23.Corbucci GG, Palmerini C, Palombari R, Lettieri B, Grella E, Velluti C, Cheio C. The nitric oxide metabolism in the hypoxic, ischemic and reperfused human skeletal muscle cell: clinical and therapeutical obsevations. Minerva Anestesiol. 2001;67:387-92.

24.Jourd'heuil D, Jourd‘heuil FL, Kutchukian PS, Musah RA, Wink DA, Grishman MB. Reaction of superoxide and nitric oxide with peroxinytrite. J Biol Chem. 2001;276:28799-805.

25.Souza AC de, Piccinato CE, Cherri J, Moriya T. Mecanismos celulares e moleculares da Lesão de isquemia e reperfusão de músculo esquelético. Cir Vasc Angiol. 2001;17:80-6.

26.Corbucci GG, Lettieri B, Damonti V, Palombari R, Arienti $\mathrm{G}$, Palmerini CA. NitricNoxide in ischemic na reperfused human muscle. Clin Chim Acta. 2002;318:79-82.

27.Wink DA, Miranda KM, Espey MG. Cytotoxicity related to oxidative and nitrosative stress by nitric oxide. Exp Biol Med. 2001;226:621-3.

28.Koksoy C, Uydes-Dogan BS, Kuzu MA, Aydemir-Koksoy A, Demirpence E, Kesenci M. Effects of intestinal ischemia-reperfusion on major conduit arteries. J Invest Surg 2000;13:35-43.

29.Moncada S. Papel del óxido nítrico en la respiracion celular. Medicina. 1998;58:357-60.

30.Bywaters EGL \& Beall D. Crush injuries with impairment of renal function. Br Med J. 1941;1:427-32. 
Correspondência:

Acacio Francisco Neto

Av. Salim Elias Bacach, 800

8790-180 - Mogi das Cruzes - SP

Tel/Fax: (11)47963970
Conflito de interesse: nenhum Fonte de financiamento: nenhuma.

Recebimento: 04/10/2004

Revisão: 09/11/2004

Aprovação: 07/12/2004

\section{Como citar este artigo:}

Francisco Neto A, Silva JCCB, Fagundes DJ, PercárioS, Novo NF, Juliano Y, Moreira Neto AA.Estudo das alterações oxidativas, da capacidade antioxidante total e do óxido nítrico, em ratos submetidos à isquemia e reperfusão de membros posteriores. Acta Cir Bras [serial online] 2005 Mar-Abr; 20(2). Disponível em URL: http://www.scielo.br/acb

*Figuras coloridas disponíveis em http://www.scielo.br/acb

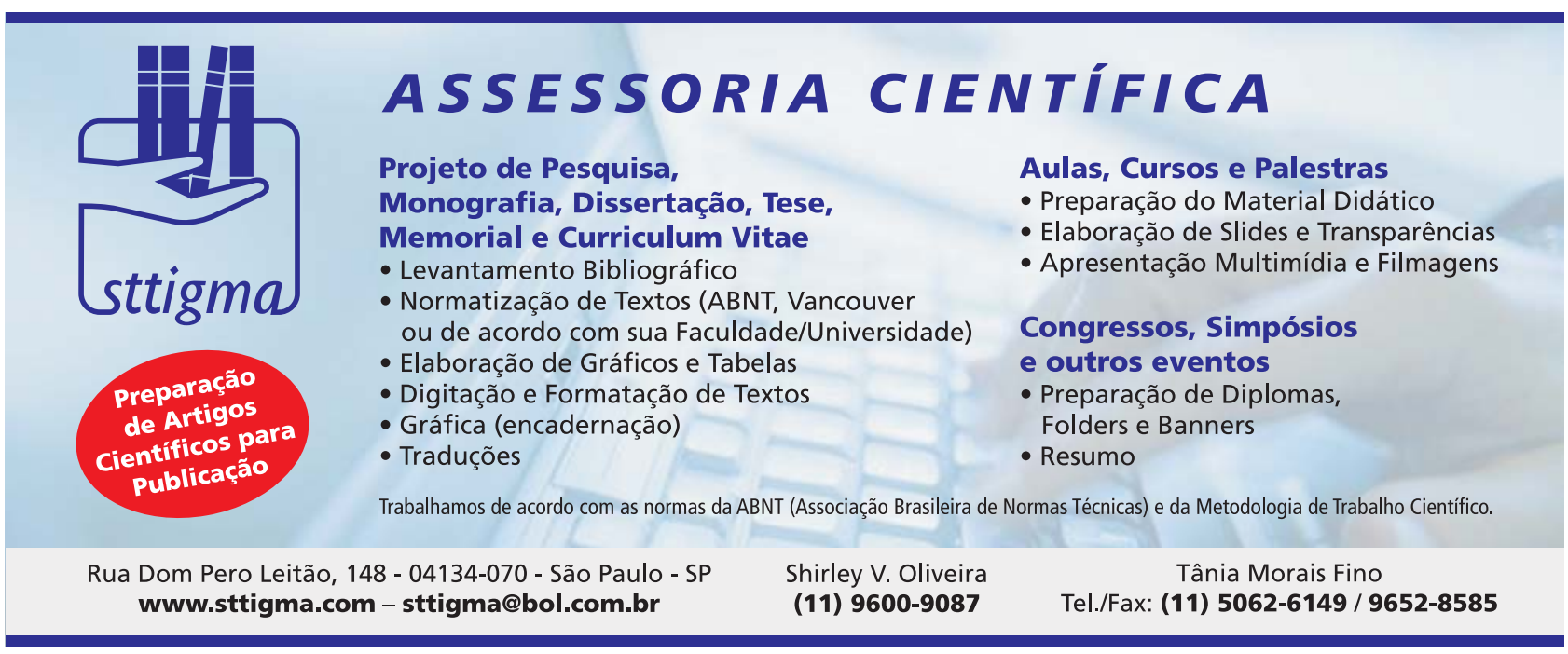

